\title{
Evolution of Standard Web Shop Software Systems: A Review and Analy- sis of Literature and Market Surveys
}

\author{
Matthias F. Treutner*, ${ }^{*}$ and Herwig Ostermann ${ }^{2}$ \\ ${ }^{1}$ University of Health Sciences, Medical Informatics and Technology, Institute for Health Information Systems, Eduard \\ Wallnöfer-Zentrum 1, A-6060 Hall in Tyrol, Austria \\ ${ }^{2}$ University of Health Sciences, Medical Informatics and Technology, Division of Health Policy, Administration and \\ Law, Eduard Wallnöfer-Zentrum 1, A-6060 Hall in Tyrol, Austria
}

\begin{abstract}
The possibility of trading goods and services over the Internet has brought fundamental changes and opened new opportunities for both buyers and sellers.

The possibilities offered by the World Wide Web (WWW) are particularly important for small and medium sized enterprises (SMEs). Using relatively modest financial resources, it has become possible to realize new business models, test new marketing possibilities and develop new markets. However, it is frequently uneconomical for SME to finance the development of its own, individual shop software solution. Complete or standard web shop systems "out of the box" offer traders an alternative.

This article reports an investigation of the development of standard web shop systems from 1995 (as the Internet and WWW became a mass medium), starting with a definition of concepts and a general presentation of the development of Internet trading. A literature search forms the basis of an examination of the functional scope of standard web shop software systems since 1995 .

The second part of the article analysis the Surveys to show how the development changes with time. This analysis leads to the definition of five phases in the development of web shop systems from 1995 until the present day and presents an evolutionary model for standard web shop systems. In the final section, currently recognizable development trends are described and their importance is evaluated for standard systems.
\end{abstract}

Keywords: E-commerce, web shop software evolution, shopping cart, online shopping system.

\section{INTRODUCTION}

E-commerce is an established component of the economy, with stable sale volumes and high acceptance, and of increasing importance for both buyers and sellers [1]. The term "e-commerce" generally refers to the electronic processing of the purchase or sale of goods and services. The majority of e-commerce sales are processed over the Internet and the World Wide Web (WWW) by means of online shops or web shops $[2,3]$.

Using this meaning as a search criterion reveals diverse studies which have the online shop as their topic and which examine, for example, success factors, user behaviour, usability and the buying experience.

"The online shop makes goods and digital products available on the Internet" [4]. In contrast, only few studies deal with the shop systems on which these online shops are based. A shop system is essentially a program mainly characterized by a shopping basket function [4]. Any necessary additional functionality depends to a large extent on the business model of the online shop operator.

*Address correspondence to this author at the University of Health Sciences, Medical Informatics and Technology, Institute for Health Information Systems, Eduard Wallnöfer-Zentrum 1, A-6060 Hall in Tyrol, Austria; Tel: + 43 (0)50 8648 - 3880; Fax: + 43 (0)50 8648 - 673853; E-mail: matthias-frank.treutner@umit.at
In Germany alone, there are currently around 200 suppliers of such systems on the market $[4,5]$, whose scope of functionality can differ greatly. The range of systems offered is wide from cost-free, simple shopping basket systems (freeware) to complex systems linked to inventory control, logistics and billing; from standard software to high-quality adaptable systems. Depending on the business model chosen, the functional scope of a web shop solution must satisfy the needs of both operator and customers [4].

Selection of a suitable, future-oriented web shop program to meet the demands of these two groups is a task that can decisively influence the success of the online shop.

The present study begins with a literature review of publications on the topic of e-commerce and, in particular, of standard web shop software, of the last 10 years.

The aim of this study is to analyze the development of the functional scope of standard web shop systems. The results of this analysis are used to identify and describe the development phases of these systems and to define the evolutionary stages.

In addition to achieving an overview of the software functionality currently demanded by and offered in the market for the operation of online shops and web shops, the results are also used to predict future development trends. 


\section{GENERAL BACKGROUND, DEFINITION OF CONCEPTS AND METHDOLOGY}

The global, and still young medium of the Internet has given rise to a large number of technical terms and names, which are often not used consistently [6]. For this reason, the present article begins by explaining and defining the terms used.

\subsection{Definitions}

E-business describes all types of business process that are implemented by electronic means. E-commerce is the sub-section of e-business in which goods and services are traded [7].

In very general terms, e-commerce refers to "computeraided business transactions that are processed over the Internet networks using other electronic techniques" [7].

E-commerce attained its current importance for trade as a result of the emergence of the Internet and, especially, of the World Wide Web (WWW): "The birth of the internet as a mass communications medium is attributed to two events driven by Marc Andreessen: the February 1993 birth of Mosaic and the March 1994 birth of Netscape as easy-to-use Graphic User Interfaces (GUIs), making the internet in general and more specifically the World Wide Web accessible to those less technically astute (...). The rampant diffusion and success of the internet (the broader colloquial term used in this article subsuming the World Wide Web) from 1994 through 2001" [8].

The terms "Internet" and "WWW" are defined in [8] as follows and identified as "key infrastructure developments that contributed to the rapid diffusion of the internet and e-commerce".

\section{Internet: diffuse, digital networking infrastructure}

2. World Wide Web (WWW): means for delivering and rendering cyber media content

As the third key infrastructure development the "mechanism for making an offer to complete a transaction in a secure environment" [8] was acknowledged (for example, secure HyperText Transfer Protocol sHTTP).

The combination of the three defined components "provides the foundation for the diffusion of e-commerce." [8].

Based on the above, new business models in ecommerce rapidly developed. Timmers [9] defines in 1998 a total of 11 e-business models, one of which was the eshop business model for B2C business, and in the year 2000, Bartelt [10] defines the online shop as an ecommerce business model.

The two terms "online shop" and "electronic" or "eshop" are used synonymously.

"Online shopping" is a term that was already being used in 1984 for TV based systems (for example) [11], long before the "birth of the WWW". For this reason, the narrower term "web shop" is used in the present study.

Software systems are necessary for the development and operation of web shops. Here too, no term has become solidly established. Whereas in the German-speaking region terms such as "web shop software" or "online shop software" are used, the term "shopping cart software" has become established in the USA as Wilson describes. "The term "shopping cart" might seem to some readers to be inadequate to describe all the functions of the modern e-commerce system. And while the authors feel that "storefront software" might be a better term, the fact is that the term "shopping cart" has been broadly adopted; therefore, that is the term ("cart" for short) we use in referring to both types of systems" [12].

Up to now it has proved impossible to find documentary evidence showing exactly when the first standard web shop systems or online shopping cart systems came into the market. Evidence is available for the market launch of the first systems in 1995. Thus Wasmeier reports in his 1997 article "Shop in the Box" on the development of the company eShop Inc., which brought its online shopping system of the same name into the market in 1995; this was later taken over by Microsoft and marketed under the name "Microsoft Commerce Server" [13].

The development of web shop systems therefore took place directly after the Internet or the World Wide Web had become a mass medium as a result of the launch of the browser Mosaic in 1993 and Netscape in 1994 [8], which created the environment in which web shops were possible.

The scope of the present study is standard software with which web-based shops (web shops) are created, managed and operated in order to sell products and services over the Internet (web shop software). In addition, the study is restricted to B2C e-commerce.

Systems for B2B trading (e-procurement) [9] are not included in the study.

\subsection{Search terms and Study Selection}

The systematic search for relevant publications took place in three stages, following the recommendations of Webster/Watson [14].

1. Search of leading databases and journals for relevant literature

2. Backward search in the references and citations listed in the publications identified

3. Forward search in scholar.google.com for publications that cite the publications identified in 1 and 2 .

The following German and English terms in different written formats (together, separated) were used, combined in each case with "software", "system", "application" or "applikation".

Search terms: Web shop, Online shop, E-shop, Warenkorbsystem, Shopping Cart, e-commerce, e-store, online store, storefront, store-building, online ordering.

The search in scientific databases and journals (ebsco and www.ebscohost.com, www.sciencedirect.com or scholar.google.com) for articles on the topic of components of web shop software systems and for market overviews took place in autumn 2009 and produced no results.

Wilson obtained the same outcome in 2006: "A search of Academic Search Premier, Business Search Premier, and TDnet for terms including "shopping cart programs," "shopping cart software," "online store software," and "storefront 
software" yielded no papers attempting to define the state of the art of the online shopping cart market" [12].

The overwhelming majority of articles was found using the above search terms that dealt with aspects of the business model of an online shop, with marketing, or with buyer behaviour. No articles were found that dealt with the technology or the software system.

Even an extended search yielded only few scientific articles dealing with the field of software systems.

In view of Wilson's comment "Trade and popular publications occasionally include reviews of online shopping cart programs" [12]. The search was also expanded to include non-scientific online resources.

Expansion of the search radius, the search terms and the use of online resources finally revealed 58 articles which conformed to the listed criteria in the title and abstract. Examination of the full text enabled a total of ten relevant articles to be identified. Seven of these were market surveys presenting the state of the technology and the functional scope of web shop systems for B2C at the respective date of publication. The results of the literature review are shown in the following section. This represents the background of the analyses how the functional scope changes with time and for the development of an evolutionary model of standard software web shop systems.

\section{RESULTS OF LITERATURE REVIEW AND STATE OF RESEARCH}

\subsection{Market Survey and Market Analysis of Web shop Software}

\section{Germany}

The handbook "Marktübersicht Online-Shops" (Market Overview of Online Shops) [15] briefly reviews over 20 software solutions currently in use (in 2009). In addition to a general survey differentiating between hosted, purchased and open source solutions, this listing also provides a brief account of the functions, interfaces and - for purchased systems - the price of each of the systems considered.

The online specialist journal commercemanager.de [5] gives a list (as at 2 August 2009) of 197 products in the following categories

- $\quad$ shop systems

- e-business solutions and

- e-marketing solutions.

The "shop systems" segment contains 75 products assigned to the following categories:

entry-level solution [total 4]

standard solutions [total 25]

enterprise solutions [total 26]

hosted shops/ASP solutions [total 15]

market place solutions [total 3]

auction solutions [total 1].

${ }^{1}$ The title "Marktübersicht Online-Shops" used here by MECK is capable of misinterpretation. In the narrower sense, "online shop" means the business model and not the software. In fact, the article discusses standard software systems.
There was no division into purchased, open source or freeware solutions.

The entries were not subject to editing. The suppliers or manufacturers themselves produced the entries, whose quality varied considerably.

The 2006 ECIN eShop Report [16] presents 57 systems in detail and provides information about each product, for example the underlying technology, the import and export possibilities, orders per day and licence model.

The oldest article found is the "Praxishilfe" (Practical Handbook) published by the German Federal Ministry for Science and Technology (BMWi): "Einsatz von Shopsystemen für E-Commerce-Anwendungen" ("Use of Shop Systems for ecommerce Applications") [17]. This Practical Handbook from the year 2001 provides basic information about the "operational aspects" of the use of e-commerce solutions. A long evaluation discusses three systems in greater detail, with functions and performance. The short evaluation provides information about seven hosted shops and 24 purchased systems with producer, brief description, features, availability (operating system, databases) and price range.

\section{English Speaking Region}

Wikipedia.org contains an entry for the term "Shopping cart software" [18] and also an entry on "Comparison of shopping cart software" [19]. This comparison discusses 30 systems and software products, with extensive product information, which are assigned to 14 areas:

The prices are given in US dollars or pounds sterling. Systems from Germany are also given, for example oxid eShop and osCommerce ([20]). All the products listed were released in 2009 or 2008. Neither a source nor a reference in print is given for this information.

"ONLINE SHOPPING CARTS: THE STATE OF THE ART" from the year 2006 was examined as a scientific contribution [12]. After defining terms, the authors present a general literature review on the topic of online shop. The typical elements of an online ordering system (SHOPPING CART FUNCTIONS) are then presented from "the shopper's viewpoint" and "the merchant's viewpoint", separated according to "basic" and "advanced" features, and the extensions of a "store building system" are defined. The final section comprises a market analysis and consideration of the "shopping cart market": “(...) we briefly review the shopping cart market itself through an examination of the types of systems vendors were offering at the time this paper was written" [12]. This market analysis identifies and describes 223 active operators and four main types of e-commerce programs:

$\begin{array}{ll}\text { - } & \text { licensed stand-alone stores } \\ \text { - } & \text { hosted ordering systems } \\ \text { - } & \text { hosted store-building systems } \\ \text { - } & \text { outsourced and third-party order handling systems. }\end{array}$

3.2. Design and Components (Architecture) of Web Shop Systems

Despite the development of numerous new business models during the period since the start of e-commerce, the basic 
design of web shop systems remains oriented on the classical type of sales process.

"No matter how varied the activities connected with online shopping might be, the essential process begins with the entry of the customer into the store and ends (possibly after several visits) with the closure of a sales contract, which is followed by transfer of the goods and payment for them" [21].

Wasmeier [21] defines the elements of a shop system according to the purchasing procedure during online shopping:

- $\quad$ storefront

- product catalogue

- if necessary, product configuration for complex products

- $\quad$ shopping cart (shopping basket)

- $\quad$ ordering system.

Merz [22] defines the basic software components of an e-shop that are as follows:

- $\quad$ shop database containing product information

- administration database

- presentation database

- recommendation engine

- $\quad$ payment gateway

- $\quad$ tools.

Dorn [23] specifies five basic components of a shop system:

- $\quad$ security system

- catalogue

- $\quad$ ordering system

- $\quad$ payment system

- $\quad$ logistics system.

Boles [24] divides the functions of e-shop systems into the three main components:

- merchandising

- $\quad$ order processing

- miscellaneous.

\subsection{Functions and Performance of Web Shop Software}

The technical components are the foundation for the widely differing functions the shop system provides for traders and customers. In this section we examine the individual functions of these systems in greater detail. The analysis is based on the market analyses already researched, and the functions listed therein. In addition, articles were examined which dealt with the functional scope of web shop software.

Bartelt [10] uses a "services approach" for identifying the elements of an online shop [10] (S. 7). In the softwareoriented treatment, the elements of an online shop are assigned from the user/customer view to the "service classes" 'basic services', added value services' and 'marketing services', and different integration models are handled in the company software.

The Practical Handbook that appeared in 2001 [17] differentiates more finely and classifies the web shop functions into seven main groups, which in one case comprises five subgroups.

Fricke [25] determines the components by means of a software analysis and on the basis of a two-dimensional reference model of electronic markets. The two dimensions are "views" and "phases". The four views are business model, transaction, market services and infrastructure. The market services view contains the shop functions, which are assigned to the four phases information, agreement, processing and after-sales.

Wilson [12] divides the functions into customer view and trader view. He describes the customer view as general demands for "convenience, security, and efficient handling of his/her order". From the view of the trader he describes five basic features and 11 advanced features.

In 2006 the ECIN also published the eShop Report Lösungen in Vergleich (Comparison of solutions) [16]. The elements and functions of an e-shop are not explicitly named in this market overview. However, they can be found in the questionnaire, which was answered by 57 e-shop software suppliers in the course of the market overview. The results showed 8 functional areas.

The Mainfränkisches Electronic Commerce Kompetenzzentrum (MECK) [15] did not consider any theoretical background in its market overview. No statements were made about selection criteria for the functions included in the overview. The function overview considered 11 functions in each case and every product was briefly described with reference to these.

Wikipedia gives a comparison of 42 software solutions (packages) [19]. The systems with the respective functions are presented in a total of 14 categories.

\subsection{Aggregated Results of Elements and Function of Web Shop Software}

The results from the literature and resource review are summarized in the following Table $\mathbf{1}$ for the sake of clarity. This table shows the chronology of the articles found and the elements and functions of web shop software systems named.

\section{WEB SHOP SOFTWARE EVOLUTION}

The review of the market overviews, the review of the elements and functions and the cited publications and other articles from the field of online shopping were used to generate a compilation of the elements and functions of online shop software products. In addition, the functions of web shop software named in the sources are collected and consolidated in a table. Terms with the same meaning and significance in more than one language were combined.

In order to improve clarity, some functions are assigned to umbrella terms (formation of clusters). The clusters are derived from the cited publications based on the classification by Bartelt [10]. The term "services" used there is replaced in the 
Table 1. Elements and Functions of Online Shop Software Systems from 2000 to 2009 in Scientific Publications and Sources Oriented on Practical Use

\begin{tabular}{|c|c|c|}
\hline Year & Elements and functions & $\begin{array}{l}\text { Practice/ } \\
\text { science }\end{array}$ \\
\hline 2000 & $\begin{array}{l}\text { Bartelt } \text { et al. [10] } \\
\text { Basic services: } \\
\text { catalogue structure / catalogue hierarchy; product and offer presentation; ordering function; billing; dealing with } \\
\text { credit cards / direct debit; session management for the user; security functions, etc. } \\
\text { Added value services: } \\
\text { search function; member / customer administration; } \\
\text { one-to-one product lists / favourites; } \\
\text { Deliverability information; availability of services } 24 / 7 \text { (continuous); order tracking; logistic tracking, etc. } \\
\text { Marketing services: } \\
\text { additional background information for customers; } \\
\text { special discounts for online shop orders; general community functions; competitions to increase customer binding, } \\
\text { etc. }\end{array}$ & science \\
\hline 2001 & $\begin{array}{l}\text { Fricke } \text { et al. }[25] \\
\text { Information phase } \\
\text { Multi-supplier catalogue: content management, catalogue search and product selection } \\
\text { Agreement phase } \\
\text { Negotiation and ordering services: order request, authorization work flow, auction, request for tenders, bourse } \\
\text { Processing phase } \\
\text { Logistics: order status/tracking, receipt } \\
\text { Payment: payment possibilities and book entry } \\
\text { After sales phase and service } \\
\text { Reporting and service: archiving, monitoring, complaint management }\end{array}$ & science \\
\hline 2006 & $\begin{array}{l}\text { Wilson } \text { et al. } \text { [12] } \\
\text { Customer/buyer view } \\
\text { convenience, security, and efficient handling of his/her order } \\
\text { Trader view: } \\
\text { Basic features } \\
\text { tax calculations; shipping calculations; secure transactions; e-mail order confirmation; keeping orders straight } \\
\text { Advanced features } \\
\text { identifying shoppers on a return visit; product databases; uploads and downloads; sales, coupons, and discounts; } \\
\text { order fulfilment and accounting integration; inventory management; store statistics; graphics; navigation systems; } \\
\text { catalogue management; selling digital products; }\end{array}$ & science \\
\hline 2006 & $\begin{array}{l}\text { ECIN eShop Report [16] } \\
\text { Shop layout, presentation and design } \\
\text { Catalogue contents, catalogue preparation and item management } \\
\text { Customer management } \\
\text { Ordering procedure, payment management and delivery management } \\
\text { Search functions } \\
\text { Marketing } \\
\text { Interfaces } \\
\text { Further modules (content management, search engine optimization, absence of barriers) }\end{array}$ & practice \\
\hline
\end{tabular}


(Table 1). Contd.....

\begin{tabular}{|c|c|c|}
\hline Year & Elements and functions & $\begin{array}{l}\text { Practice/ } \\
\text { science }\end{array}$ \\
\hline 2009 & $\begin{array}{l}\text { Wikipedia.com [19] } \\
\text { General information } \\
\text { Data storage } \\
\text { General features } \\
\text { Customer features } \\
\text { Customer reward features } \\
\text { Administration area features } \\
\text { Search engine optimization features } \\
\text { Security features } \\
\text { Other features } \\
\text { Payment gateway support } \\
\text { Alternative checkout support } \\
\text { Real time shipping calculation } \\
\text { Shipment booking integration } \\
\text { Shipment tracking integration }\end{array}$ & practice \\
\hline 2009 & $\begin{array}{l}\text { Merck [15] } \\
\text { Item/category number } \\
\text { Shopping basket } \\
\text { Layout } \\
\text { Self-contained customer area } \\
\text { Recording and processing customers' buying behaviour } \\
\text { Acceptance of General Terms of Trade when ordering } \\
\text { Security } \\
\text { Integrated e-mail system } \\
\text { Availability display } \\
\text { Customer classification } \\
\text { Search functions }\end{array}$ & practice \\
\hline
\end{tabular}

following by the term "function", leading to a differentiation between basic functions, added value functions and marketing functions. The large number of functions offered in the publications and in practice renders further subdivision necessary. For this purpose, the fields used in the market overview in Wikipedia.com [19] are analyzed in greater detail, reduced, and combined with the author's own experience to derive the following umbrella functions:

- $\quad$ Storefront features/Product presentation features

- Customer features (customer specific functions)

- Customer reward features (customer reward, customer benefit, award)

- $\quad$ Marketing features

- $\quad$ Administration features (administration functions)

- $\quad$ Order management features and logistic features

- $\quad$ Search engine optimization features

- $\quad$ Security features

The results are presented in Table 2: Development of the elements and functions of online shop software products.

When interpreting this table, it must be borne in mind that the underlying articles deal with standard software systems.
The table shows that the scope of functions increases over the years. A comparison of the scientific text from Bartelt [10] from the year 2000 with the study by Wilson in 2006 [12] reveals that the number of features and their emphasis have shifted. The administrative functions are gaining importance.

The comparison among the practically oriented articles also shows an increase in the functional scope. It is noteworthy, however, that the current articles in Wikipedia.com [19] and [15] do not name specific basic functions - for example catalogue function, product database and order function - explicitly as functions. This is probably because these are sources from practice and these functions, being essential for any shop system, are not considered worth mentioning explicitly.

\section{STAGES OF WEB SHOP SOFTWARE EVOLUTION (EVOLUTIONARY STAGES)}

Analysis of the table shows that the number of functions of web shop software is increasing and the focus of the functions has shifted with time. This can be used to derive the evolutionary stages of web shop system software.

The early shop systems focused primarily on the presentation of offers (storefront system) and on copying the traditional buying process through the web shop system [24]. Thus Wasmeier in 1997 stated "If a satisfactory Internet shopping solution appropriate to the business software in use does not 
Table 2. Development of the Elements and Functions of Online Shop Software Products

\begin{tabular}{|c|c|c|c|c|c|c|c|c|}
\hline Umbrella terms & Functions & 2000 & 2001 & 2001 & 2006 & 2006 & 2009 & 2009 \\
\hline \multirow[t]{6}{*}{ Storefront } & Catalogue function & $\mathrm{X}$ & $\mathrm{X}$ & $\mathrm{X}$ & & $\mathrm{X}$ & & \\
\hline & Shopping basket & & & $\mathrm{X}$ & & & $\mathrm{X}$ & \\
\hline & Product and offer presentation & $\mathrm{X}$ & $\mathrm{X}$ & & & $\mathrm{X}$ & & \\
\hline & Multi-lingual & & & & & $\mathrm{X}$ & & \\
\hline & Sale of digital products & & & & $\mathrm{X}$ & $\mathrm{X}$ & & $\mathrm{X}$ \\
\hline & Barrier free & & & & & $\mathrm{X}$ & & \\
\hline \multirow{2}{*}{$\begin{array}{l}\text { Customer fea- } \\
\text { tures }\end{array}$} & Search function & $\mathrm{X}$ & $\mathrm{X}$ & $\mathrm{X}$ & & $\mathrm{X}$ & $\mathrm{X}$ & $\mathrm{X}$ \\
\hline & $\begin{array}{l}\text { General community functions (social book- } \\
\text { marks, tell a friend, wish list, polls) }\end{array}$ & $\mathrm{X}$ & & & & & & $\mathrm{X}$ \\
\hline \multirow[t]{2}{*}{$\begin{array}{l}\text { Customer reward } \\
\text { features }\end{array}$} & $\begin{array}{l}\text { Customer specific marketing functions (member- } \\
\text { ship sale, membership coupons, membership } \\
\text { discounts) }\end{array}$ & & $\mathrm{X}$ & & $\mathrm{X}$ & $\mathrm{X}$ & & $\mathrm{X}$ \\
\hline & Special discounts for online shop orders & $\mathrm{X}$ & & & & & & \\
\hline \multirow{2}{*}{$\begin{array}{l}\text { General market- } \\
\text { ing features }\end{array}$} & Campaigns & & $\mathrm{X}$ & & & & & \\
\hline & Evaluation and analysis functions & & $\mathrm{X}$ & & $\mathrm{X}$ & $\mathrm{X}$ & & $\mathrm{X}$ \\
\hline \multirow{10}{*}{$\begin{array}{l}\text { Administration } \\
\text { features }\end{array}$} & Product database & & & & $\mathrm{X}$ & $\mathrm{X}$ & & \\
\hline & Session management & $\mathrm{X}$ & & & $\mathrm{X}$ & & & \\
\hline & Design tools/template engine & & $\mathrm{X}$ & & & $\mathrm{X}$ & $\mathrm{X}$ & $\mathrm{X}$ \\
\hline & Content management (CMS) & & & $\mathrm{X}$ & & $\mathrm{X}$ & & \\
\hline & Administration components & & $\mathrm{X}$ & & & $\mathrm{X}$ & & $\mathrm{X}$ \\
\hline & Member/customer management & $\mathrm{X}$ & & & & $\mathrm{X}$ & $\mathrm{X}$ & \\
\hline & Customer registration & & & & $\mathrm{X}$ & $\mathrm{X}$ & $\mathrm{X}$ & $\mathrm{X}$ \\
\hline & Customer groups (e.g. B2B, B2C) & & & & & & $\mathrm{X}$ & \\
\hline & Import/export (customer data, products, etc.) & & & & $\mathrm{X}$ & & $\mathrm{X}$ & $\mathrm{X}$ \\
\hline & Interfaces & & & $\mathrm{X}$ & & $\mathrm{X}$ & & $\mathrm{X}$ \\
\hline
\end{tabular}


(Table 2). Contd.....

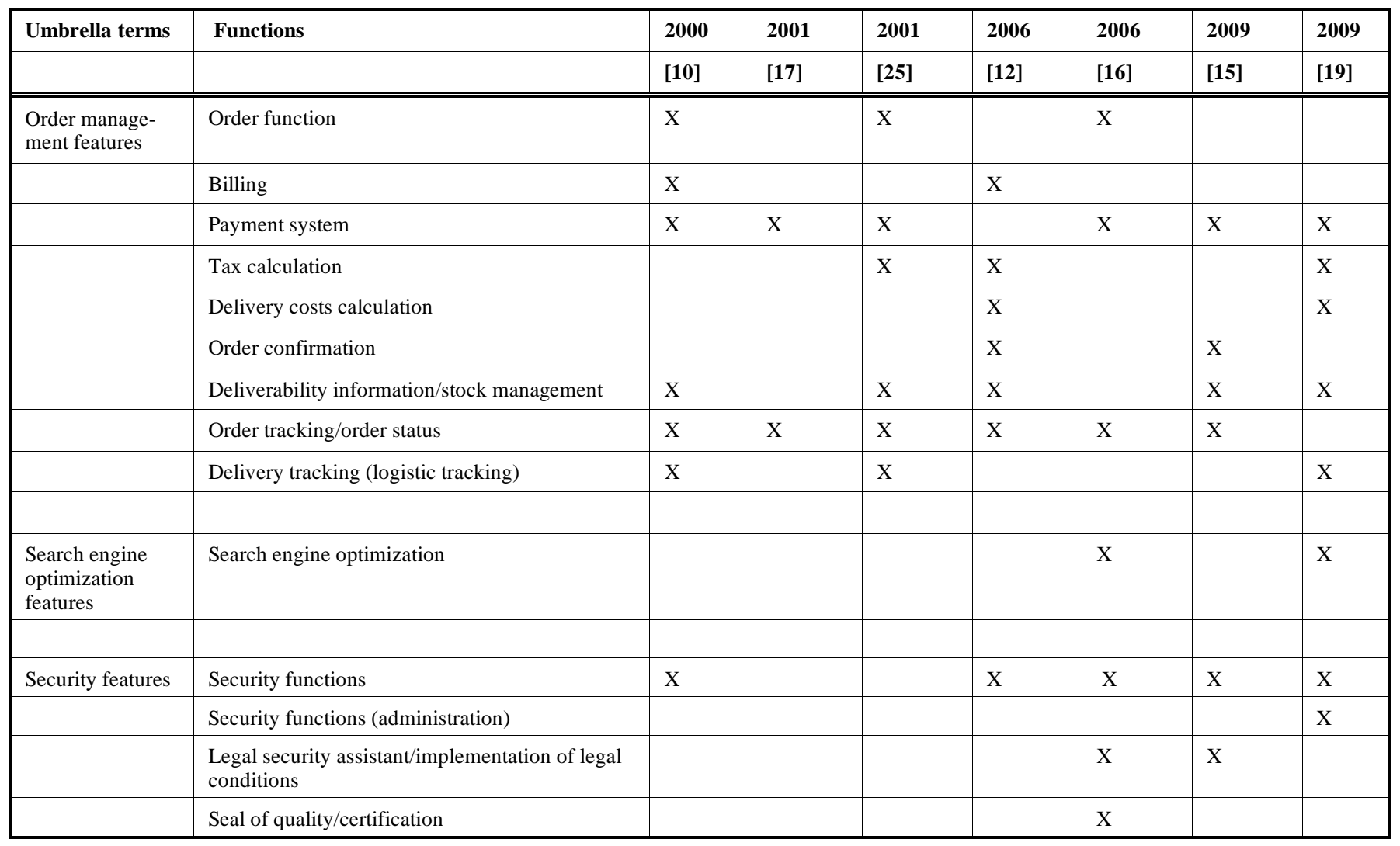

already exist (most plans of this kind are still in the development stage), the shop operator is faced with a considerable investment" [21].

It was not yet possible to illustrate the complete trading process: "end-to-end IS solutions for online retailing were not available" [26]. The adaptation of individual systems that could already offer a high level of integration required considerable effort. In 1997, out-of-the-box solutions were still a vision of the future [21]. "The applications that came close, such as Broadvision's One-To-One Server and OpenMarket's Transact/LiveCommerce, were not "out-ofthe-box" solutions. Instead, the rich functionality and flexibility of these applications came at the expense of high design complexity and extensive programming efforts" [26].

The next step in the development of standard web shop systems was the integration of the back-end business processes in the sales process. In 2000, Langdon describes the lack of back-end integration as a challenge to be faced: "Two additional problems complicated the e-back-end challenge. First, the back-end information systems had to be integrated with the store front-end applications and with existing legacy systems of channels partners, such as distributors and parent companies" [26].

Also in the year 2000, Bartelt [10] goes beyond the "basic services" such as the presentation of products and offers, and defines integration in the enterprise and coordination with the inventory management systems as part of an online shop concept. From 2000 onwards, the development of the "storefront system" to the "order management system" also becomes evident in web shop systems. In the systems examined in 2001, these requirements were implemented in terms of functional scope $[17,25]$. In the articles from 2001 to 2006 the administration functions gain importance $[12,16]$. The demands of the traders are met, who need a simple integration and coordination of the business processes. However, these functions also have positive effects and benefit the customer as a result of professional processing of the business, or customer administration. This leads to a new stage of development: differentiation possibilities and competitive advantages as a result of customer features.

From 2006, orientation on using the software becomes evident, with the shop systems providing better support for the buyers. The software systems focus on the customer and functions to support the customer - such as help functions, background information for customers or customized product overview pages combined with availability of the customer preferred colour and size .

Changing and completely new e-commerce business models have now started to appear in the standard software systems. The articles from 2009 [15, 19] verify this increase in customer oriented functions such as customer and customer reward features and also in the customer related security functions.

This allows the evolutionary stages of web shop systems to be defined.

These stages and the resulting evolutionary model are presented in the following table (Fig. 1). The Figure was inspired by [27]. 


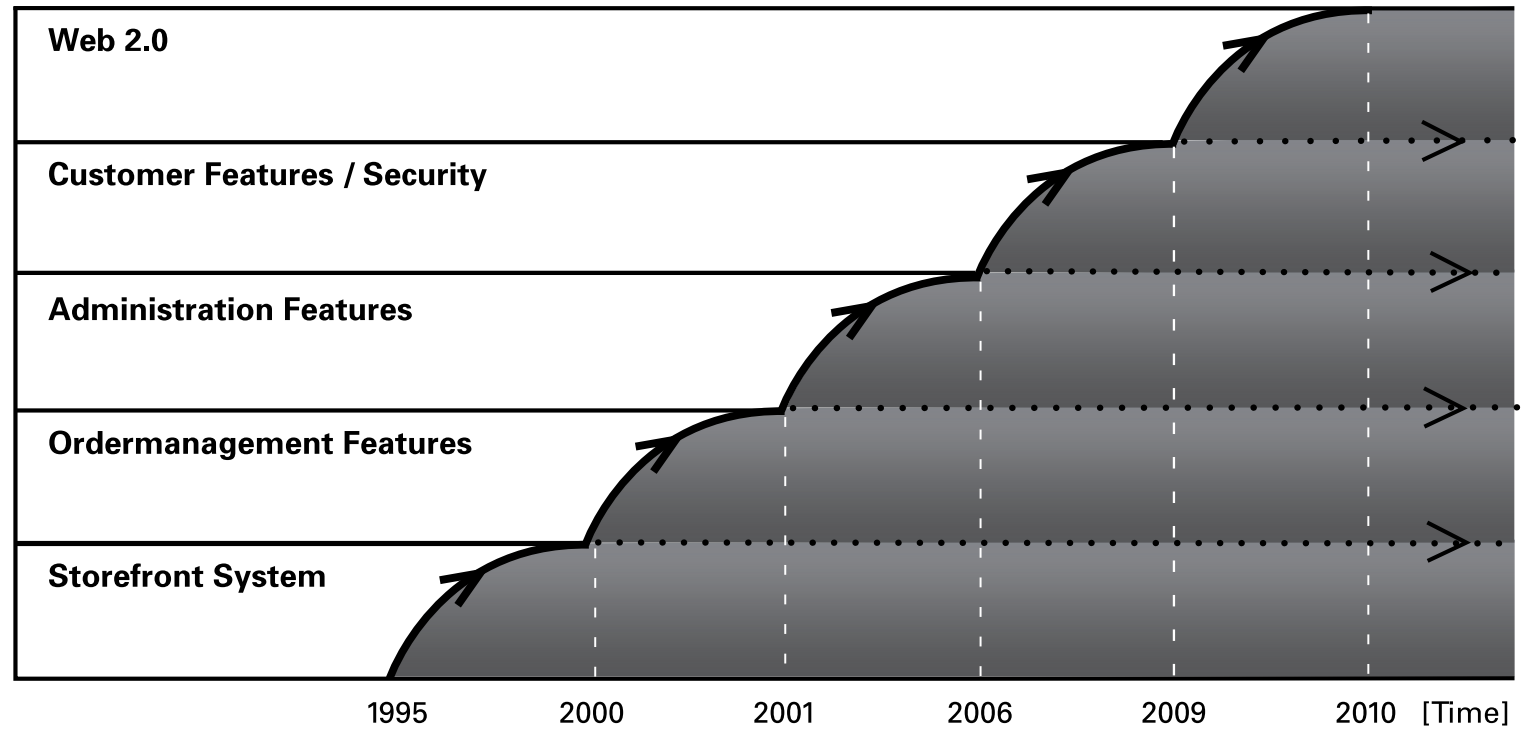

Fig. (1). Evolutionary stages of web shop systems from 1994 to 2009 and 2010 trend.

\section{The Next Evolutionary Stage}

Analysis of the customer features reveals a new trend in online shopping. This is generally called social commerce, in B2C in particular, as social shopping. Social shopping denotes the integration of the users in the online shop by "consumer generated content" [28], for example social bookmarks or Customer Testimonials [19]. The web shop becomes a platform onto which the user can bring active content. "The shop turns into a community and the consumer to a fully integrated content distributor" [28].

The first social shopping functions are already part of the standard software systems.

In this way, the trend towards integration of customer oriented functions continues, and now is expanded by functions that first became possible via the medium Internet [29]. In addition, the shop even becomes the foundation on which new developments brought in by users become possible. According to O'Reilly, [30] the first principle of Web 2.0 is "the web as platform". The definition of Web 2.0 actually includes more than the social web. Services here play a central role. "Services, not packaged software, with cost-effective scalability". Mashups services, for example, are applications which generate new, innovative applications from data and content of external sources [29].

In his study [28], Leitner analysis "100 future B2B und B2C e-commerce models" and identifies 4 trends:

"Crowdsourcing: Working steps are sourced out to the users and collective intelligence is used in e-shops. The grade reaches from small functions to fully integrated product life cycles and user generated marketing.

Live shopping: Through real time functionalities and the use of life media, a special user experience is guaranteed. For example a consumer can see the percentage of sold products per hour.

Mass customization: According to his wishes, the customer has the ability to configure products online. For ex- ample, every user can print his own logo or picture on several standard products.

Shopping widgets: Little tools or applications, which have special functions, can be included in blogs or other social networks. Shopping widgets are opening new marketing channels to vendors."

"Live shopping" and "Mass customizing" are functions that belong to the customer features stage.

"Crowdsourcing" and "shopping widgets" are functions at a high technical level with considerable involvement of the customer and they therefore comply with the definition of Web 2.0 applications. Two of the four e-commerce model trends identified are based on Web 2.0. A few standard shop systems like $x t$ :commerce already offer their own social commerce functions or the integration of specific functions from social network portals like facebook ${ }^{2}$. On the other hand, a new business model is available for social network projects, since up to now many of these projects do not yet operate profitably or, at least, financing by membership subscriptions alone is not possible. "Without doubt, the acceptance of the communication platforms is high among the users - as long as it costs nothing. As a result, it is difficult for the platform operators to make a profit - because despite all the oaths of allegiance, only few users pay a membership contribution to their virtual society. And fee-charging premium services also meet with little interest" [31].

The coming evolutionary stage of standard web shop systems is Web 2.0.

\section{CONCLUSIONS}

Standard web shop systems have passed through different development phases during the last 15 years.

Initially, the driving force behind the development was cost savings while retaining traditional business models. "From an

${ }^{2}$ Facebook Funktionen in xt:Commerce: http://www.xt-commerce.com/blog/xtcommercetips/facebook-funktionen-in-xtcommerce-veyton.html 
economic perspective, the development of electronic commerce is first and foremost driven through transaction cost savings" [26]. The focus on the presentation of offers at the beginning of the development was soon superseded. Increasing sale volumes and number of customers demanded better and better integration of the shop into the trader's back-end processes.

Whereas initially passing on the cost benefits to the customer was sufficient differentiation, increasing competition made it necessary to seek other distinguishing possibilities.

The new possibilities offered by the Internet promoted a large number of new business models which focus on the customer.

The development can be divided into three phases:

Phase 1: Focus on presentation of offers and products transfer of the traditional shop to the Internet

Phase 2: Trader focus - integration of the web shop in the back-end process

Phase 3: Customer focus - creation and securing competitive advantages by customer participation.

The Internet and the demands made by business on the software systems are - and always were - situated in a rapidly changing environment. The dynamic development of the possibilities generated by the medium creates new needs and new challenges for the traders and final customers of such systems. This leads to shorter and shorter product cycles, which are presented in this paper as identifiable stages of evolution.

The sheer magnitude of online competition and the associated high market and price transparency force Internet traders to achieve differentiation of their shops by means of criteria other than simply the price.

Involvement of the customer as designer and codeveloper of the range of items and, in the end, also of the shop solution represents one possibility of differentiation and the creation of competitive advantages.

Large online shopping sites like Amazon.com and shopping communities like www.brands4friends.de already use social web features and the first standard web shop systems already include social networks.

The new opportunities opened by means of Web 2.0 should be used by the producers of standard software in order to be able to offer smaller and medium sized online traders appropriate functions for their web shops.

\section{REFERENCES}

[1] E. Stahl, T. Krabichler, M. Breitschaft, and G. Wittmann, ECommerce-Leitfaden: Erfolgreicher im elektronischen Handel, 2. überarbeitete und erweiterte Auflage, Regensburg: Univ.-Verl. Regensburg, 2009. Avalible at: http://www.gbv.de/dms/zbw/ 599251085.pdf

[2] Online-Shopping in Deutschland weit verbreitet, Presseinformation. Berlin, 2009. http://www.bitkom.org/files/documents/ BITKOM_Presseinfo_E-Commerce_21_05_2009.pdf (accessed December 30, 2009).

[3] Bundesministerium für Wirtschaft und Technologie (BMWi), ed., 2. ePerformance Report - Sonderbericht anlässlich des Zweiten Nationalen IT-Gipfels, 2007.
[4] Elektronischer Handel - Wikipedia, 2009. http://de.wikipedia.org/ wiki/Elektronischer_Handel (accessed February 6, 2011).

[5] Commercemanager.de - Das E-Commerce Portal: Commercemanager.de - Marktübersicht: F\&P GmbH - FEiG \& PARTNER - Verlag für Online-Fachmagazine, 1999-2011. http://www.commercemanager.de/itguide/marktuebersicht.html (accessed February 8, 2011).

[6] S. Seemüller, Durchsatzberechnung automatischer Kleinteilelager im Umfeld des elektronischen Handels, Techn. Univ., Diss. München, 2005. Fördertechnik - Materialfluss - Logistik. München, Utz, 2006.

[7] K. C. Laudon, J. P. Laudon, and D. Schoder, Wirtschaftsinformatik: Eine Einführung, 2., aktualisierte Aufl. WI - Wirtschaft. München: Pearson Studium, 2010.

[8] G. C. Ariguzo, E. G. Mallach, and D. S. White, "The first decade of e-commerce", Int. J. Business Inform. Sys., vol. 1, no. 3, pp. 239-55, 2006.

[9] P. Timmers, "Business Models for Electronic Markets", Electronic Markets - Int. J. Network. Business, vol. 8, no. 2, pp. 3-8, 1998. Avalible at: http://www.electronicmarkets.org/issues/volume8/volume-8-issue-2/businessmodels0.pdf

[10] A. Bartelt, H. Weinreich, and Winfried Lamersdorf, Kundenorientierte Aspekte der Konzeption von Online-Shops. Virtuelle Organisation und Neue Medien 2000. Köln: Josef Eul Verlag Lohmar, 2000. Avalible at: http://vsis-www.informatik.uni-hamburg.de/getDoc.php/ publications/80/Bartelt2000-OnlineShops.pdf

[11] Online shopping - Wikipedia, the free encyclopedia, 2009. Avalible at: http://en.wikipedia.org/wiki/Online_shopping (accessed December 30, 2009).

[12] R. F. Wilson, J. B. Pettijohn, and S. D. McMurtrey, "Online Shopping Carts: The State-of-the-Art", J. Internet Commun., vol. 5, no. 2, pp. 75-94, 2006. Avalible at: http://www.informaworld.com/ 10.1300/J179v05 n02_05.

[13] M. Wasmeier, "Shop in the Box: Komplettlösungen für Online-Shops von iCat, Intershop und Microsoft", Magazin für Computer Technik $C T$, no. 11, pp. 226-40, 1997.

[14] J. Webster and R. T. Watson, "Guest Editorial: analyzing the past to prepare for the future: writing a literature review," MIS Quart., vol. 26, no. 2, pp. xiii-xxiii, June 2002. Avalible at: http://www.misq. org/archivist/vol/no26/issue2/GuestEd.pdf (accessed October 10, 2009).

[15] Mainfränkisches Electronic Commerce Kompetenzzentrum (MECK), Marktuebersicht Online-Shops. Würzburg, 2009. Avalible at: http:// www.meck-online.de/wp-content/uploads/2010/01/13/ebusinessdownloads/2009-03-16-Marktuebersicht-Online-Shops.pdf

[16] eShop Report - Lösungen im Vergleich - ECIN - Electronic Commerce Info Net, 2006. Avalible at: http://www.ecin.de/shops/ report2006/ (accessed February 8, 2011).

[17] CeCNW, OFFIS RECO, Einsatz von Shopsystemen für ECommerce-Anwendungen: Eine Praxishilfe zur Nutzung des Internet für Electronic Commerce für kleine und mittlere Unternehmen (KMU). Praxishilfe des BMWi, 2001. Available at: http:// sp91393062.officehosting.de/Tipps\%20\%20Tricks/Online-Shopsysteme.pdf

[18] Shopping cart software - Wikipedia, the free encyclopaedia, 2009. Available at: http://en.wikipedia.org/wiki/Shopping_cart_software (accessed February 8, 2011).

[19] Comparison of shopping cart software - Wikipedia, the free encyclopaedia, 2010. Available at: http://en.wikipedia.org/wiki/Comparison_ of_shopping_cart_software (accessed May 17, 2010).

[20] osCommerce - Wikipedia, the free encyclopaedia, 2009. Available at: http://en.wikipedia.org/wiki/OsCommerce (accessed February 8, 2011).

[21] M. Wasmeier, "Shop in a Box: Funktionsweise von Online-ShopKomplettpaketen", Magazin für Computer Technik -CT, no. 7, p. 268, 1997.

[22] M. Merz, Electronic Commerce: Marktmodelle, Anwendungen and Technologien, 1. Auflage Heidelberg: dpunkt.-verl., 1999.

[23] L. Dorn, G. Hammer, and J. Knuth, E-Commerce in deutschen Unternehmen - mit einer empirischen Untersuchung in kleinen und mittleren Handelsunternehmen des Landes Bremen, Anwendungen Status Quo - Perspektiven - Qualifikationen. Bremen, 2001. http://www.iaw.uni-bremen.de/downloads/NEMO-3-e-commerce.pdf

[24] J. Heinrich Jasper, J. Küng, and G. Vossen, Eds., DDS: Ein ShopSystem Für Den Information Commerce, Tagungsband EMISA-2000 Fachtagung. Informationssysteme für E-Commerce (Schriftenreihe 
Informatik) 4. Linz, 2000. Available at: http://wwwis.informatik.uni-oldenburg.de/ dibo/paper/dds-emisa2000.pdf

[25] M. Fricke, and M. Gauder, Standardsoftware für elektronische Märkte: Softwareanalyse und Bewertung, Frankfurt: Institut für Wirtschaftsinformatik (IWI) - Johann Wolfgang GoetheUniversität, 2001.

[26] C. S. Langdon, and M. J. Shaw, "The Online Retailing Challenge: Forward Integration and E-Backend Development": European Conference on Information Systems (ECIS) 2000, 2000.

[27] Accenture, E-Government 2003: Ergebnisse einer internationalen Vergleichsstudie, Abbildung 2: Stufen der E-GovernmentEntwicklung. Kronberg i.T., 2003. Avalible at: http://www.informatik.sg.ch/home/egovernment/publikationen/studien.Par.001 5.DownloadListPar.0017.File.tmp/Accenture_egov_2003.pdf

[28] P. Leitner and T. Grechenig, Next Generation Shopping: Case Study Research On Future E-Commerce Models: Iadis Interna- tional Conference e-Commerce 2007, 2007. Avalible at: http://www. iadis.net/dl/final_uploads/200715C046.pdf

[29] P. Leitner and T. Grechenig, "Collaborative Shopping Networks: Sharing the Wisdom of Crowds in E-Commerce Environments", 21st Bled eConference eCollaboration: Overcoming Boundaries through Multi-Channel Interaction, Bled, Slovenia, 2008. Avalible at: http://domino.fov.uni-mb.si/proceedings.nsf/Proceedings/824F8A6A C21D3F99C125748100440406/\$File/25Leitner.pdf

[30] T. O'Reilly, What Is Web 2.0 - O'Reilly Media, 2005. Avalible at:http://oreilly.com/web2/archive/what-is-web-20.html (accessed February 8, 2011).

[31] Nutzer Sozialer Netzwerke sind treu - doch beim Geld hört die Freundschaft auf: PricewaterhouseCoopers, 2008. Avalible at: http:// www.pwc.de/portal/pub/!ut/p/c4/04_SB8K8xLLM9MSSzPy8xBz9 CP0os3gDA2NPz5DgAF9nA0dPN3M_V0tnAwjQL8h2VAQAXrjp Rg!!/?topNavNode $=49 \mathrm{c} 411$ a4006ba50c $\&$ siteArea $=49 \mathrm{cbd} 5 \mathrm{c} 0 \mathrm{e} 668 \mathrm{~d} 28$ $2 \&$ content $=$ e52522060b1069f (accessed June 7, 2010).

(c) Treutner and Ostermann; Licensee Bentham Open.

This is an open access article licensed under the terms of the Creative Commons Attribution Non-Commercial License (http://creativecommons.org/licenses/by-nc/3.0/) which permits unrestricted, non-commercial use, distribution and reproduction in any medium, provided the work is properly cited. 